\title{
Research on the Influencing Factors of Shadow Education Input Selection Based on Grounded Theory
}

\section{-From the perspective of parents}

\author{
Su Ke \\ Xi'an University of Posts \& Telecommunications, Xi'an 710061, China. \\ sukeforever@163.com
}

Keywords: Shadow education; Investment choice; Influencing factors; Grounded theory

\begin{abstract}
Based on the in-depth interviews with the parents of 30 students in an educational institution in Xi'an, this paper uses the rooted theory and the Nvivo qualitative analysis software to find out the factors affecting parents' choice for extracurricular tutoring through the open, related and selected three-level coding analysis, including external factors (information acquisition, herd, family environment), internal factors (parental subjective willingness, parental objective conditions), child situation (children's subjective will, child's objective conditions) and training institution environment (soft environment, hard environment). Based on this, a model of the influence factors of parents' shadow education selection is constructed to provide useful guidance for parents and education and training workers.
\end{abstract}

\section{Introduction}

Shadow education, or "extracurricular tutoring", generally refers to the supplementary supplementary education implemented outside the formal education system for the purpose of improving the academic performance or broadening interest of the students in the school. The training content is mainly at the school. Courses, hobbies and hobbies, mainly for primary and secondary school students. Mark Bere's article "The Challenge of Shadow Education: EU Family Education and Its Impact on Policy Makers" states that "shadow education" has flourished and spread to Europe. According to relevant survey data, Poland's freshman who just entered school $48.9 \%$ of students in the middle school stage received private counseling; $60.5 \%$ of the students surveyed in Hungary had private tutoring in high school, and about $75 \%$ had private tutoring in primary school; Romania received sample survey $50 \%$ of parents asked their children for tutoring; $62 \%$ of the college students surveyed in Lithuania had tutored in the last year of high school; in the past 10 years, the scale of extracurricular tutoring in Western Europe has also expanded rapidly. In the UK, about $12 \%$ of primary school students and $8 \%$ of secondary school students have invited tutors. In France, about 25\% of primary school students and 33\% of middle school students have invited tutors. [1]

With the continuous advancement of quality education in China, students are encouraged to develop in a comprehensive and diversified manner. Under the pressure of the examination system 
of evaluation and admission, shadow education has sprung up in the country and has developed rapidly, forming a shadow education institution and shadow education with specific forms. Mode, shadow education has become an indispensable form of education in the national education system. According to the latest survey report on the status quo of teachers in China's counseling education industry and counseling institutions, the number of students participating in the national competition in 2016 exceeded 137 million, and about 68.5\% of the students in Beijing, Shanghai, Shenzhen and other big cities participated in tutoring. There are about 7 million to 8.5 million teachers in tutoring institutions, and the amount of tutoring education exceeds 800 billion yuan. For half of the households in China, the expenditure on shadow education has accounted for about $70 \%$ of family education expenditure. [2] English, interest quality and mathematics are the most common categories of children participating in tutoring. In 2017, the penetration rate of domestic key education and training institutions among existing users: $64.0 \%$ of interest quality, $52.5 \%$ of children's enlightenment knowledge, $46.5 \%$ of English, $13.5 \%$ of study tour, mathematics 8.0; average parents let children participate in 2 Kindergarten tutoring. [3]

In view of the above-mentioned "extracurricular counseling fever" status, this study will discuss the following two aspects: First, which factors have an impact on parents' choice of extracurricular tutoring classes; second, after obtaining these influencing factors, rationalizing parental tutoring Suggest.

\section{Literature References}

When studying the shadow education in Turkey, Tansel and Bircan found that parents' participation in education, family income, family residence, age of the head of household, number of children, family of single parents, etc. Extracurricular tutoring has a significant impact [4]. Jelani and Tan analyzed the influence of family background factors of Malaysian pupils on extracurricular tutoring opportunities, and found that students' family income had a significant impact on family extracurricular tutoring opportunities. [5] Kim (Kim) explored the influence of Korean extracurricular tutoring on students with different academic performances by adding pre-school academic scores and whether to participate in the interactive project of shadow education. The results show that the positive impact effect of shadow education on the top academic students is significant. Higher than the impact on students who are ranked lower in academics. [6]

Xue Haiping and Ding Xiaohao's analysis of the factors influencing whether urban students participate in extracurricular tutoring in China shows that family capital factors such as family economic income and education level of heads of household have a significant impact on whether urban students participate in extracurricular tutoring; [7] Chu Hongli research finds families Family capital factors such as economic income, parental education, and parents' educational expectations significantly affect the probability of extracurricular tutoring. [8] The research conclusions of Zeng Manchao et al. showed that family background factors had a significant impact on the choice of extracurricular tutoring for junior high school students. [9] Hong Yanbi and Zhao Yandong examined the impact of family capital on the opportunities for tutoring in urban compulsory education in China, and found that family cultural capital, economic capital and social capital have a significant positive impact on whether compulsory education students participate in shadow education. . For parents with higher education, their children are significantly more likely to participate in shadow education than their parents have no higher education. The higher the monthly income per household, the higher the probability that their children will participate in shadow education. Parents' occupational skills in the lower middle and upper middle classes are significantly higher than those in the parental occupation. [10] 


\section{Research design}

The grounded theory was first proposed by the two American scholars Barney Glaser and Anselm Strauss in 1967, The Discovery of Grounded Theory. of. [11] Follow the bottom-up research logic, have a systematic coding idea, gradually summarize and refine the theory from the data, and finally achieve the purpose of understanding the world, instead of using the data verification theory, can avoid relying on experience only under the empirical paradigm. The one-sidedness produced by the theoretical model. Therefore, the grounded theory is suitable for analyzing theoretical phenomena with local characteristics and immature. At present, grounded theory has been widely used in the fields of management, psychology, sociology and education.

\subsection{Data collection}

In-depth interviews are the most commonly used method in classical grounded theory research. Chen Xiangming believes that through verbal communication, individuals can express their own ideas, and different individuals can achieve certain mutual understanding. Through questions and conversations, people can transcend themselves and approach the fusion of subjective domains to construct new ones. Social reality that is meaningful to both parties. [12] This study uses open questions, self-designed semi-structured in-depth interview outlines, interviews with 30 parents of an educational institution, and the interviews mainly focus on the following aspects:

(1) What extracurricular tutoring class have you chosen for your children?

(2) Why did you choose those classes above?

(3) What are the main factors you considered when you chose those classes?

During the interview process, the author maintained a listening attitude throughout the interview and strived for an easy interview atmosphere. In order to avoid missing important information, the interview was recorded throughout the process after obtaining the consent. Finally, there are 26 valid data for parents, each of which lasts approximately 15 to 20 minutes. The 26 sample data were randomly divided into 20 and 6 copies, the former used for rooted theoretical data coding and the latter used for theoretical saturation test.

\subsection{Data analysis}

Open coding was performed in the manner of Table 1, and a total of 38 concepts were obtained. Through further analysis of the concept, 15 new and more general categories are obtained, as shown in Table 2.

Linked logins are designed to discover and establish relationships between concepts and refine the main categories. On the basis of existing concepts and categories, re-read the original materials, summarize the original concepts, and finally extract the external factors (information acquisition, congregation, family environment), internal factors (parental subjective willingness, parental objective conditions) The child's situation (child's subjective will, child's objective conditions) and the training institution's environment (soft environment, hard environment) are four main categories. The relationship between the main category and the category and the connotation of the category are shown in Table 3. 
Table 1 open coding

\begin{tabular}{|c|c|}
\hline original material & \\
\hline $\begin{array}{l}\text { My child is now in the third grade. Currently, he has reported calligraphy, } \\
\text { go and English classes. Since the first exam will involve the Olympics, the } \\
\text { next semester will also give the child another Olympic class. As far as the } \\
\text { current child's time is concerned, it has already been arranged full, } \\
\text { especially when it is time to play Go and Olympia in the evening, and } \\
\text { basically write homework at } 10 \text { o'clock in the evening. Once you report } \\
\text { another Olympiad in the next semester, your child's burden may be } \\
\text { heavier, But if you don't register it, there is no way. If you don't sign up, } \\
\text { you can't keep up. } \\
\text { I told my children that calligraphy and English were introduced by friends } \\
\text { and colleagues. I heard that the teachers taught well and their children } \\
\text { were there, so they signed up naturally. Go is because I am close to home. } \\
\text { I and my lover walked in the evening and didn't want to find it. I went up } \\
\text { and sat down. I consulted, and everything in the environment feels good. I } \\
\text { heard that Go is good for developing intelligence. It was very helpful, so I } \\
\text { signed up. } \\
\text { I mainly want to enroll my child in the remedial class. I still consider the } \\
\text { child's interest, but there is no way to do it like English and Olympiad. The } \\
\text { exam is there. In addition, we will consider the environment of the training } \\
\text { institution and the distance from home. Now the child's time is really } \\
\text { precious. Even if you teach well, but the distance is too far, there is no } \\
\text { way. }\end{array}$ & $\begin{array}{l}\mathrm{a}_{5} \text { Congregational psychology } \\
\mathrm{a}_{6} \text { Friend and colleague } \\
\text { introduction } \\
\mathrm{a}_{7} \text { Training institution environment } \\
\mathrm{a}_{8} \text { Others'evaluation } \\
\mathrm{a}_{9} \text { Child interest } \\
\mathrm{a}_{10} \text { Examination pressure } \\
\mathrm{a}_{11} \text { Distance }\end{array}$ \\
\hline
\end{tabular}

Table 2 categorization of concepts

\begin{tabular}{|c|c|c|}
\hline Number & Concept & Category \\
\hline 1 & $\begin{array}{l}\text { Friends and colleagues, WeChat friends, flyers, } \\
\text { advertisements }\end{array}$ & Information accessing \\
\hline 2 & $\begin{array}{c}\text { Acquaintance's choises, acquaintance } \\
\text { evaluation }\end{array}$ & Congregational psychology \\
\hline 3 & Family support, family harmony, parent family & family environment \\
\hline 4 & $\begin{array}{l}\text { Study tasks, exam pressures, too much homework } \\
\text { assignments }\end{array}$ & Academic pressure \\
\hline 5 & Child interest, talent & Subjective willingness of children \\
\hline 6 & $\begin{array}{l}\text { Children's age, gender, grade at school, school } \\
\text { attendance, personality traits, children's spare time }\end{array}$ & Children's objective situation \\
\hline 7 & Parents'age, work, income, education background & Parental objective conditions \\
\hline 8 & $\begin{array}{c}\text { Complete own wishes, parents' understanding } \\
\text { of extracurricular tutoring classes, educational } \\
\text { philosophy }\end{array}$ & Parents' subjective views \\
\hline 9 & $\begin{array}{c}\text { Curriculum, brand, word of mouth, teaching } \\
\text { form, teacher, teacher status, teaching level, course } \\
\text { price }\end{array}$ & $\begin{array}{l}\text { Training institutions’soft } \\
\text { environment }\end{array}$ \\
\hline 10 & $\begin{array}{l}\text { Training institutions' environment, hardware } \\
\text { facilities, geographical location }\end{array}$ & $\begin{array}{l}\text { Training institutions' hard } \\
\text { environment }\end{array}$ \\
\hline
\end{tabular}


Table 3 Main category extraction

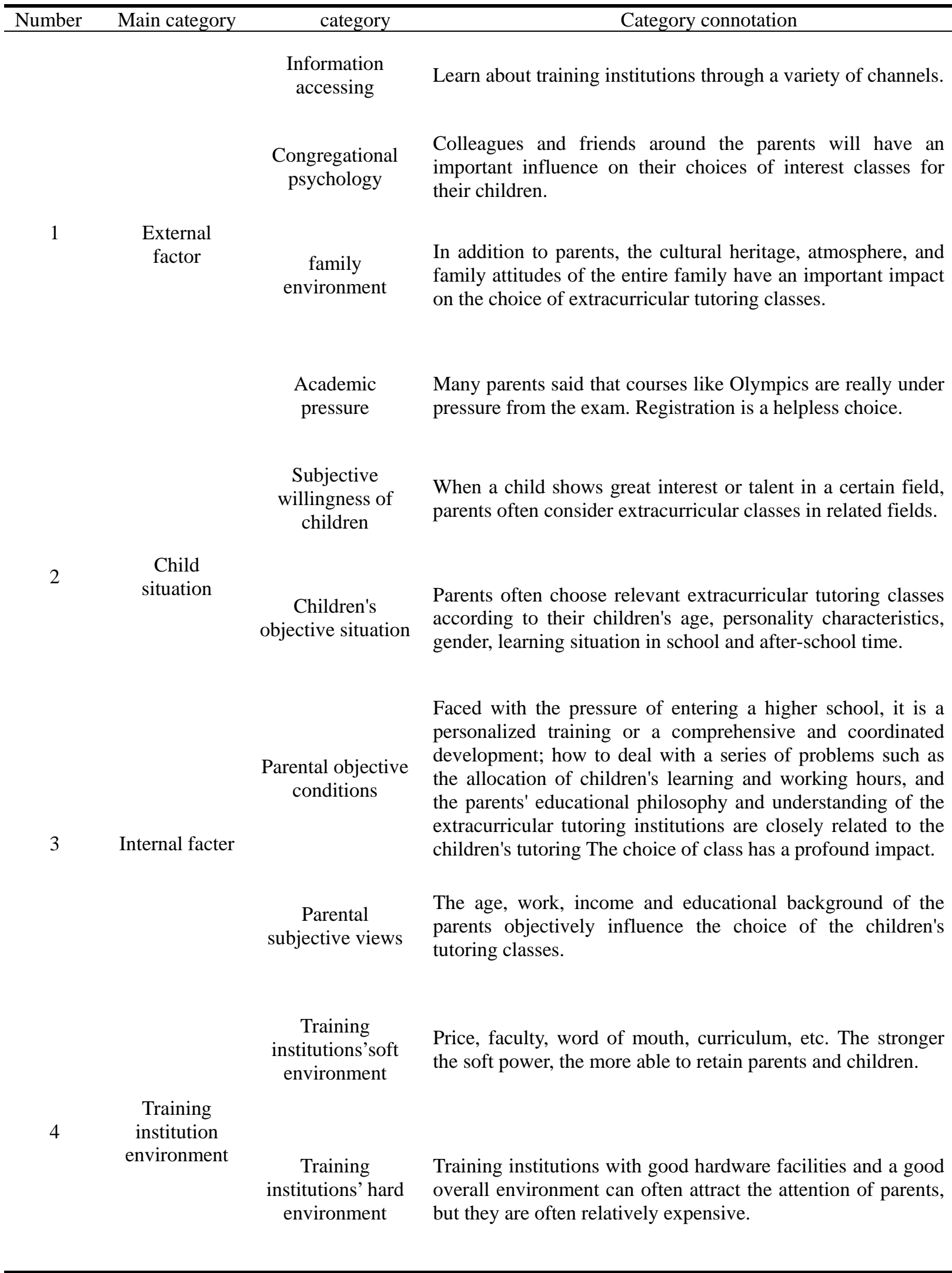

According to the four main categories of external factors, internal factors, children's situation and 
institutional environment, the research model of the influence factors of shadow education input selection is constructed, as shown in Figure 1.

\subsection{Saturation test}

The theoretical saturation test aims to find out if there are new concepts and categories. The six interviews were reserved for the saturation test according to the above three steps. No new concepts and categories were found. Therefore, the study believes that based on the parents' interview data, the model of the influence factor of parents' shadow education input selection is theoretically saturated.

\section{Conclusions and Suggestions Affecting Parents' Choice of Extracurricular Remedial Classes}

With the rooted theory, through the in-depth interview analysis of parents, there are four factors that affect parents' choice of extracurricular tutoring classes:

They are internal factors, children's situation, external factors and training institution environment. Among them, the internal factors include the parents' subjective will and objective conditions; the children's situation mainly covers the child's own subjective will and its objective conditions; the external factors refer to the parents' access to information, the herd mentality and the family environment; Including soft and hard environments. At the same time, according to the open-coded original sentence and the category connotation results in the spindle coding, parents can provide reference for the selection of training institutions for their children.

\subsection{From the perspective of parents themselves, there are the following suggestions:}

(1) Parents should rationally choose extracurricular tutoring classes on the basis of respecting children. The study found that some parents blindly forced their children to participate in extracurricular tutoring classes according to their own preferences, hoping that their children could fulfill their unfulfilled wishes or goals. This attitude of looking into a child and becoming a woman is worthy of recognition, but it is often counterproductive. This will cause the child to have a premature lack of interest, and investing time and money will not achieve the desired results.

(2) Parents should deepen their understanding of counseling institutions before enrolling. Parents should fully understand all aspects of the counseling institution before enrolling their children in extracurricular remedial classes, including teachers, curriculum forms, fees, environment, and geographic location. At the same time, consider the objective situation of their children and finally make a choice. Many parents have not done enough before the registration, and a series of disputes concerning the organization's teachers, curriculum, and fees have often occurred, resulting in time-consuming and laborious efforts.

(3) Parents should constantly improve their educational philosophy and maintain an open mind. Many parents blindly follow the crowd, seeing others learn to want their children to learn, and reported a lot of training classes for their children. The children rushed around the school and training classes all day long, but they were too busy to learn. When parents sign up for extracurricular remedial classes, they should pick one or two courses that are of interest to the child, and insist on not giving up easily, and will eventually gain something.

\subsection{From the perspective of parents versus children, the recommendations are as follows:}

Parents should fully consider the child's age, grade, gender, personality, school situation, after 
school time and other objective factors, targeted choice of extracurricular tutoring classes. In terms of age and grade, the middle and lower grades of primary school often have more spare time, and can choose more extracurricular tutoring classes to observe the children's points of interest. After the child enters the middle and upper grades, with the increase of homework and schoolwork burden, the children can be rationally screened according to their interests. In terms of gender and personality, don't be prejudiced. If you don't hold a boy, you should learn the ball. The girl should learn the solid idea of drawing and dancing. Take the child's interest as the starting point and rationally choose the training institution.

\subsection{From the perspective of the family environment, the recommendations are as follows:}

From the interview data, we found that a warm and harmonious family environment is a prerequisite for children to receive excellent educational resources. Among the 30 parents interviewed, 24 said that their family relationship is stable and can provide a good learning environment for their children. Most importantly, a stable family relationship can often be a good division of labor around the child. Earn money to support the family, pick up, counseling, each family member to do a division of labor within the division, to achieve twice the result with half the effort.

\section{Conclusion}

According to the research paradigm of grounded theory, this study obtained first-hand original data through in-depth interviews with parents. The data has authenticity and high practical significance. After open coding, spindle coding, selective coding and saturation test, the four main categories of internal factors, children's situation, external factors and training institution environment were obtained. Information acquisition, congregation, family environment, pressure for further education, parents Subjective willingness, parental objective conditions, subjective willingness of children, objective conditions of children, soft environment of training institutions, hard environment of training institutions, and other sub-categories of parents are the influencing factors model for children's shadow education. In the current hot wave of children's training, theoretical research is scarce, and few studies using grounded theory are the novelty and uniqueness of this article. Finally, according to the theoretical model obtained, from the four orientations of parents, children, families and training institutions, combined with the actual situation of the current training industry, parents can provide reasonable suggestions for children's shadow education choices, in order to provide parents who are choosing and will choose. Provide useful guidance.

\section{References}

[1] Yang Hongliang. The Challenge of Shadow Education: EU Family Education and Its Impact on Policy Makers: Interpretation and Enlightenment [J].Foreign primary and secondary education, 2012.

[2] China Education Association. Survey report on the status quo of teachers in China's counseling education industry and counseling institutions [EB/OL].[2016-12-30].http://www.jynet.org/news.html.

[3] 2017 China Education and Training Industry White Paper. [EB/OL].http://www.199it.com/archives/653691.html

[4] Tansel,A.,\& Bircan,B,F. Private Supplementary Tutoring in Turkey Recent Evidence on Its Various Aspects[EB/OL]. https://ssrn.com/abstract=1122804.

[5] Jelani, J., \& Tan, A. K. Determinants of participation and expenditure patterns private tuition received by primaryschool students in Penang, Malaysia: An exploratory study. [J] Asia Pacific Journal of Education,2012,32 (1).

[6] Kim ,H. Analysis of the Effects of Private Education on Academic Achievvement and labor Market Performance [R].KDI Reports,2010,(50):1-15.

[7] Xue Haiping, Ding Xiaohao. Research on Tutoring of Urban Student Education in China[J]. Educational Research, 2009, (1) 
[8] Chu Hongli. Background characteristics and personal factors of extracurricular tutoring families in primary and middle school students in China [J]. Educational Monthly, 2009, (12).

[9] Zeng Manchao, Ding Xiaohao, Shen Hua. Analysis of the Differences Between Urban and Rural Students in Extracurricular Tutoring in Junior Middle School_-Based on the Investigation of Extracurricular Tutoring of Junior Middle School Students in Gansu, Hunan and Jiangsu Provinces[J].Education and Economy,2010,(2).

[10] Hong Yanbi, Zhao Yandong. From Capital to Habitus: The Stratum Differentiation of Urban Family Education Model in China [J].Social Sciences Research, 2014,(4).

[11] Glaser,B.\& Strauss,A.(1967).The discovery of grounded theory: Strategies for qualitative research. Chicago: Aldine Publishing Company, 1967.

[12] Chen Xiangming. Qualitative research methods and social science research [M]. Beijing: Education Science, 2001: 169. 